\title{
Erratum to: Genre Changes and Privileged Pedagogic Identity in Teaching Contest Discourse
}

\section{Erratum to:}

N. Liu and D. Irwin, Genre Changes and Privileged

Pedagogic Identity in Teaching Contest

Discourse, SpringerBriefs in Education, DOI 10.1007/978-981-10-3686-6_7

In the original version of the book, the book series title "SpringerBriefs in Linguistics" has to be changed to "SpringerBriefs in Education". The erratum book has been updated with the change. 